\title{
Polymer-mediated dendritic growth of a transition metal salt crystal as a template for morphogenesis
}

\author{
Yuya Oaki, Ryo Muramatsu and Hiroaki Imai
}

Dendritic morphologies of a metal oxide, metal and conductive polymer were obtained by using the dendrites of a transition metal salt as a template. Dendrites of the transition metal salt, copper acetate monohydrate $\left(\mathrm{Cu}\left(\mathrm{CH}_{3} \mathrm{COO}\right)_{2} \cdot \mathrm{H}_{2} \mathrm{O}\right)$, were prepared under diffusion-controlled conditions in a polymer matrix, such as poly(vinyl alcohol; PVA). The resultant dendrites of $\mathrm{Cu}$ $\left(\mathrm{CH}_{3} \mathrm{COO}\right)_{2} \cdot \mathrm{H}_{2} \mathrm{O}$ acted as a self-template and were converted to divalent copper oxide (CuO) by the thermal treatment with the removal of PVA. The macroscopic CuO dendritic shapes consisting of the nanocrystals were obtained, and the resultant CuO was reduced to metallic copper $(\mathrm{Cu})$ without morphological changes. The dendritic morphologies of polypyrrole (PPy) were obtained by the diffusion of pyrrole (Py) vapor to the $\mathrm{Cu}\left(\mathrm{CH}_{3} \mathrm{COO}\right)_{2} \cdot \mathrm{H}_{2} \mathrm{O}$ dendrites, which acted as the reactive template. The oxidative polymerization of Py provided PPy in the PVA matrix. These results suggest that the approach to morphogenesis presented herein can be applied to other metal oxides, metals and polymers.

Polymer Journal (2015) 47, 183-189; doi:10.1038/pj.2014.113; published online 10 December 2014

\section{INTRODUCTION}

Morphology control is an important technique in materials science. ${ }^{1-4}$ Biominerals are inorganic-organic composites with controlled morphologies. In biomineralization, crystal morphologies are controlled by biological macromolecules under mild conditions. Inspired by the biological processes, a variety of inorganic-organic fusion materials have been prepared through molecular-control techniques. ${ }^{5-16}$ In molecular-control processes, the organic molecules influence crystallization of inorganic materials by a variety of interaction schemes. The interaction between the crystal faces and the additive molecules induces morphology changes through habit modification. ${ }^{17-20}$ The oriented nanocrystals, namely mesocrystals, are obtained through the sequential crystal growth with the interaction of the additive organic molecules. ${ }^{21-26}$ The organic macromolecules serve as templates for growth of inorganic crystals. ${ }^{27-32}$ The diffusioncontrolled conditions for crystal growth are achieved in the polymer matrices. Morphology variation emerges from the combination of these interaction schemes. If these effects are tuned in a synthetic system, inorganic-organic fusion materials with complex morphologies can be designed by molecular-control processes.

A variety of morphologies have been observed on crystals grown in a polymer and gel matrices. ${ }^{27-41}$ In general, kinetically controlled growth of crystal proceeds under low supersaturated conditions in the absence of polymer matrices. ${ }^{42}$ In contrast, diffusion-controlled growth is achieved in the polymer matrices because the diffusion of the solutes is limited in the presence of macromolecules. ${ }^{9,14,31}$ Kato and co-workers reported on the crystallization of calcium carbonate $\left(\mathrm{CaCO}_{3}\right)$ in a variety of polymer matrices. ${ }^{5,7,27-30,43-53}$ The patterned inorganic-organic composites were obtained in the polymer matrices on substrates. Our group has studied morphological variation in crystals from polyhedrons to dendritic morphologies with an increase in the density of polymer matrices. ${ }^{31}$ The two-dimensional patterns of barium nitrate were prepared in a polymer matrix. ${ }^{40,41}$ When the unit crystals formed the polyhedral shapes with the lower symmetry, the twisted accumulation of the unit crystals were observed in the polymer matrices. ${ }^{36-39}$ These previous works suggest that the diffusioncontrolled condition has an important role for crystal growth in polymer matrices. In general, patterned architectures are fabricated by top-down approaches, such as lithography. However, they could also be obtained easily by crystal growth in polymer matrices as a bottomup approach. Our intention here is the use of the dendritic crystals grown in polymer matrices as a self-template for morphogenesis of the other materials. The dendritic morphologies of a metal oxide and a metal were prepared from the dendrites of a transition metal salt. The present method can be applied as a bottom-up approach for the morphogenesis of materials.

Conductive polymer materials have attracted much interest in recent years. It is not easy to achieve simultaneous control of the synthesis and morphogenesis of conductive polymers. ${ }^{54-57}$ The morphology control was achieved by using templates, such as selfassembled molecules and nanospace host materials. ${ }^{58,59}$ In a previous report, the composites of monovalent copper oxide $\left(\mathrm{Cu}_{2} \mathrm{O}\right)$ and $\mathrm{PPy}$ were prepared by the oxidative polymerization on the divalent copper oxide $(\mathrm{CuO})$ nanoplates. $^{60}$ In the present work, we adopted the vapor-phase polymerization technique for such morphogenesis. The dendritic crystals of $\mathrm{Cu}\left(\mathrm{CH}_{3} \mathrm{COO}\right)_{2} \cdot \mathrm{H}_{2} \mathrm{O}$, a transition metal salt, were 


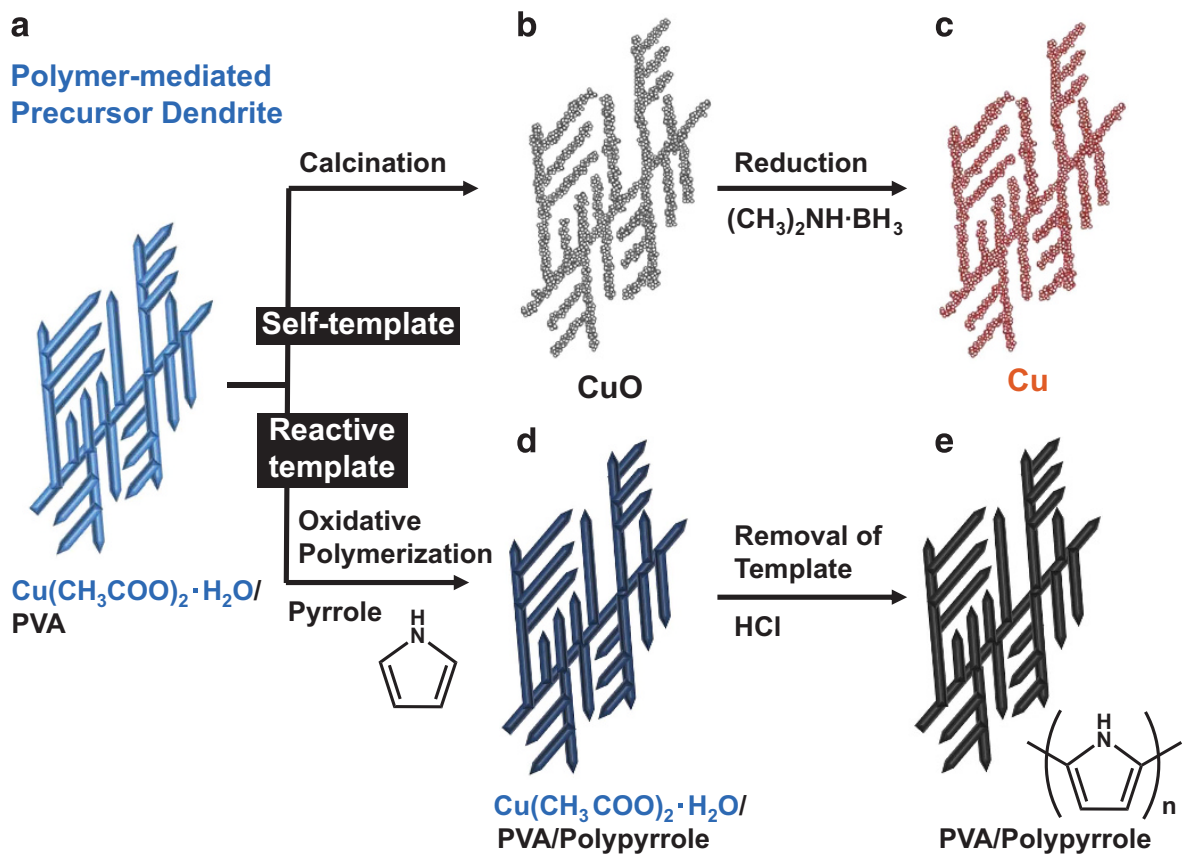

Figure 1 Schematic illustrations of the dendritic morphologies obtained in the present work. (a) Precursor $\mathrm{Cu}\left(\mathrm{CH}_{3} \mathrm{COO}_{2} \cdot \mathrm{H}_{2} \mathrm{O}\right.$ dendrite grown in a poly(vinyl alcohol; PVA) matrix. (b) $\mathrm{CuO}$ synthesized via the thermal treatment of the precursor $\mathrm{Cu}\left(\mathrm{CH}_{3} \mathrm{COO}\right)_{2} \cdot \mathrm{H}_{2} \mathrm{O}$. (c) Metallic $\mathrm{Cu}$ prepared via the reduction of $\mathrm{CuO}$ by immersion in aqueous dimethylamine borane (DMAB) solution as a reducing agent. (d) PPy formed with the $\mathrm{Cu}\left(\mathrm{CH}_{3} \mathrm{COO}_{2} \cdot \mathrm{H}_{2} \mathrm{O}\right.$ dendrite in the PVA matrix. (e) PPy/PVA composite obtained after the dissolution of the copper-related compounds by $\mathrm{HCl}$.

used as both a template and an oxidative agent. PPy is synthesized by oxidative polymerization from Py. Because Py vapor was supplied to the dendritic crystals of $\mathrm{Cu}\left(\mathrm{CH}_{3} \mathrm{COO}\right)_{2} \cdot \mathrm{H}_{2} \mathrm{O}$, PPy was formed by the oxidative polymerization on the dendritic crystals. The dendritic morphology of PPy was maintained after the dissolution of the copper-related compounds. The present approach using the morphology-controlled reactive template can be regarded as a new method for the morphogenesis of conductive polymer materials.

Figure 1 summarizes the scheme of the present work. The original dendrites of $\mathrm{Cu}\left(\mathrm{CH}_{3} \mathrm{COO}\right)_{2} \cdot \mathrm{H}_{2} \mathrm{O}$ crystals were grown in a matrix of poly(vinyl alcohol; PVA). The thermal treatment of the original $\mathrm{Cu}$ $\left(\mathrm{CH}_{3} \mathrm{COO}\right)_{2} \cdot \mathrm{H}_{2} \mathrm{O}$ with the PVA film provided the $\mathrm{CuO}$ dendritic morphology with a porous structure (Figures $1 \mathrm{a}$ and $\mathrm{b}$ ). The dendritic shapes of metallic $\mathrm{Cu}$ were formed by the subsequent reduction of the $\mathrm{CuO}$ (Figure 1c). When the original $\mathrm{Cu}\left(\mathrm{CH}_{3} \mathrm{COO}\right)_{2} \cdot \mathrm{H}_{2} \mathrm{O}$ dendrite with the PVA film was set in a sample bottle with the neat liquid of Py monomer, the diffusion of Py vapor induced the oxidative polymerization around the dendrite (Figures $1 \mathrm{a}$ and $\mathrm{d}$ ). The composite film of PPy and PVA with the dendritic morphology was eventually obtained after the dissolution of the original dendrite (Figures $1 \mathrm{~d}$ and e). The present work shows a new bottom-up approach for the morphogenesis of materials, such as metal oxides, metals and conductive polymers.

\section{EXPERIMENTAL PROCEDURE}

\section{Preparation of $\mathrm{Cu}\left(\mathrm{CH}_{3} \mathrm{COO}\right)_{2} \cdot \mathrm{H}_{2} \mathrm{O}$ crystals in PVA matrices}

The precursor solutions containing $0.5-5.0 \mathrm{~g}$ of $\mathrm{Cu}\left(\mathrm{CH}_{3} \mathrm{COO}\right)_{2} \cdot \mathrm{H}_{2} \mathrm{O}$ (Kanto, Tokyo, Japan, $99.0 \%$; $C_{\mathrm{Cu}} \mathrm{g}^{-1}$ in $100 \mathrm{~g}$ of water) and $0-3.0 \mathrm{~g}$ of PVA (Jusei, Tokyo, Japan, $M_{\mathrm{w}}=22 \times 10^{3}$; $C_{\mathrm{PVA}} \mathrm{g}^{-1}$ in $100 \mathrm{~g}$ of water) were prepared in $100 \mathrm{~g}$ of purified water. The aqueous solution of PVA was prepared in purified water at $80-100{ }^{\circ} \mathrm{C}$. After cooling, $\mathrm{Cu}\left(\mathrm{CH}_{3} \mathrm{COO}\right)_{2} \cdot \mathrm{H}_{2} \mathrm{O}$ was added in the PVA aqueous solution at room temperature. Upon dissolution of the materials, $5 \mathrm{~cm}^{3}$ of the precursor solution was poured in a polystyrene (PS) vessel $(64 \mathrm{~mm}$ in length, $35 \mathrm{~mm}$ in width and $9 \mathrm{~mm}$ in height). A cleaned glass slide (62 $\mathrm{mm}$ in length and $26 \mathrm{~mm}$ in width) was set at the bottom of the vessel. The PS vessel was maintained at $25^{\circ} \mathrm{C}$, with a slope of $1^{\circ}$, without sealing and under ambient pressure and moisture. After the evaporation of water, the crystals were deposited on the surface of glass substrates.

\section{Syntheses of $\mathrm{CuO}$ and $\mathrm{Cu}$ from the original dendrite of $\mathrm{Cu}$ $\left(\mathrm{CH}_{3} \mathrm{COO}\right)_{2} \cdot \mathrm{H}_{2} \mathrm{O}$}

The resultant dendrite of $\mathrm{Cu}\left(\mathrm{CH}_{3} \mathrm{COO}\right)_{2} \cdot \mathrm{H}_{2} \mathrm{O}$ formed at $C_{\mathrm{Cu}}=1.0$ and $C_{\mathrm{PVA}}=1.0$ on the substrate was placed in a furnace set at $500^{\circ} \mathrm{C}$ without the temperature elevation steps under air atmosphere. After $1 \mathrm{~h}$, the substrate was withdrawn from the furnace immediately. The gradual heating and cooling processes were not included in the present treatment. The resultant $\mathrm{CuO}$ on the substrate was immersed in an aqueous solution containing $10 \mathrm{mmol} \mathrm{dm}^{-3}$ of dimethylamine borane (DMAB, Wako, Osaka, Japan, 97.0\%) as a reducing agent for $3 \mathrm{~h}$

Syntheses of PPy on the original dendrite of $\mathrm{Cu}\left(\mathrm{CH}_{3} \mathrm{COO}\right)_{2} \cdot \mathrm{H}_{2} \mathrm{O}$ The resultant $\mathrm{Cu}\left(\mathrm{CH}_{3} \mathrm{COO}\right)_{2} \cdot \mathrm{H}_{2} \mathrm{O}$ dendrite crystals on a substrate were immersed in a glass vessel containing an excess amount of Py neat liquid in a separate sample bottle. The sample bottle was sealed and then maintained at $60^{\circ} \mathrm{C}$ for $24 \mathrm{~h}$. The withdrawn substrate was dried at $60^{\circ} \mathrm{C}$ under ambient pressure to evaporate the excess monomers adsorbed on the surface. The remaining copper-related compounds were dissolved by immersion of the substrate in an aqueous solution containing $0.1 \mathrm{~mol} \mathrm{dm}^{-3}$ hydrochloric acid ( $\mathrm{HCl})$ for $15 \mathrm{~h}$.

\section{Characterization}

The morphologies of the structures were observed by optical microscopy (Keyence, Osaka, Japan, VHX-1000 and Olympus, Tokyo, Japan, BX-51-FL), scanning electron microscopy (Keyence VE-9800) and field-emission scanning electron microscopy (FEI, Hillsboro, OR, USA, Sirion and Hitachi, Tokyo, Japan, S-4700). Amorphous osmium was coated on the surface of the sample to ensure the conductivity. Energy dispersive X-ray (Bruker AXS, Yokohama, Japan, Quantax) spectroscopy was performed on the field-emission scanning 
a
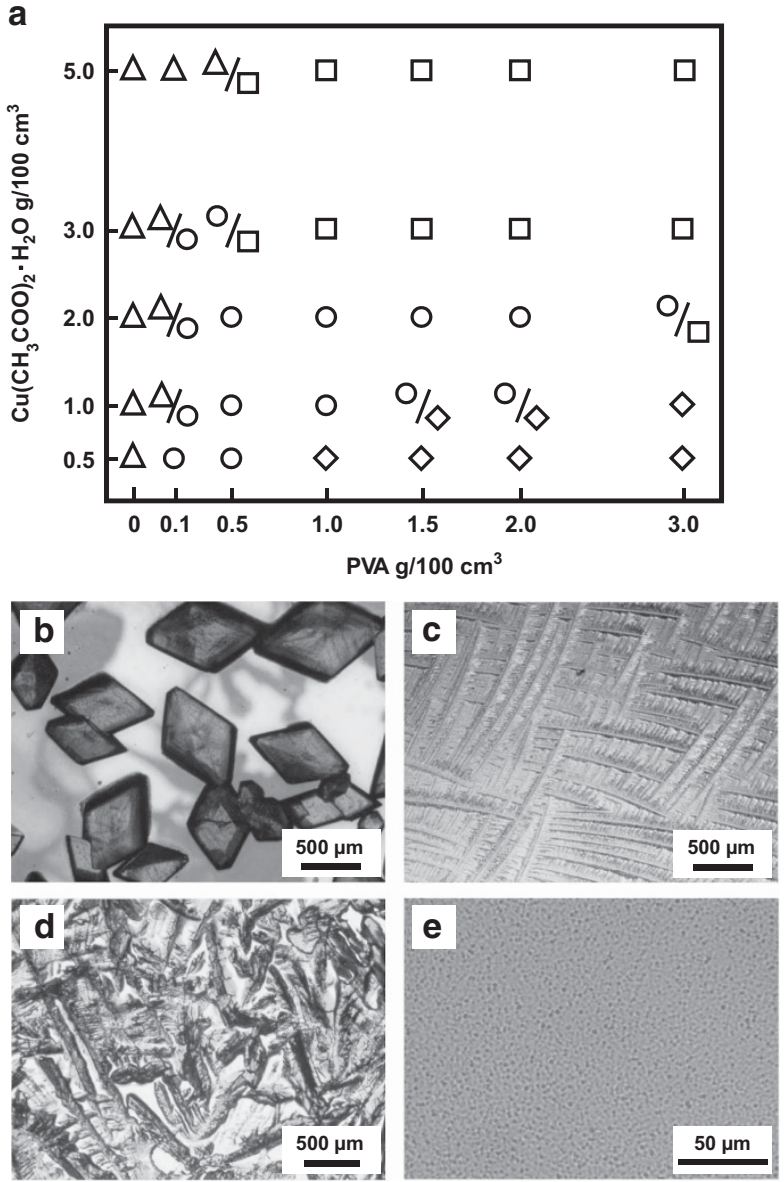

Figure 2 Variation in the morphology of $\mathrm{Cu}\left(\mathrm{CH}_{3} \mathrm{COO}\right)_{2} \cdot \mathrm{H}_{2} \mathrm{O}$ crystals grown in poly(vinyl alcohol; PVA) matrices. (a) Summary diagram showing morphology variation from polyhedral shapes (triangles) to regular dendrites (circles), irregular dendritic shapes (squares) and microparticles (diamonds) with changes in $C_{\mathrm{Cu}}$ and $C_{\mathrm{PVA}}$. (b-e) Optical microscope images of polyhedral shapes (b), regular dendrites (c), irregular dendritic shapes (d) and microparticles (e), respectively. A full color version of this figure is available at Polymer Journal online. electron microscopy observation. The crystal structure and growth direction were analyzed by X-ray diffraction (XRD; Rigaku, Tokyo, Japan, MiniFlexII) with a $\mathrm{CuK \alpha}$ radiation. The formation of PPy and the presence of the acetate groups in $\mathrm{Cu}\left(\mathrm{CH}_{3} \mathrm{COO}\right)_{2} \cdot \mathrm{H}_{2} \mathrm{O}$ and the $\mathrm{OH}$ groups in PVA were analyzed by Fourier-transform infrared absorption (FT-IR; JASCO, Tokyo, Japan, FT-IR 4200ST). The FT-IR analyses were performed by the KBr method.

\section{RESULTS AND DISCUSSION}

\section{Morphology variation of $\mathrm{Cu}\left(\mathrm{CH}_{3} \mathrm{COO}\right)_{2} \cdot \mathrm{H}_{2} \mathrm{O}$ crystals in PVA} matrices

The $\mathrm{Cu}\left(\mathrm{CH}_{3} \mathrm{COO}\right)_{2} \cdot \mathrm{H}_{2} \mathrm{O}$ crystals were obtained with the PVA film on a glass substrate after the evaporation of water from the precursor solution. The morphology of $\mathrm{Cu}\left(\mathrm{CH}_{3} \mathrm{COO}\right)_{2} \cdot \mathrm{H}_{2} \mathrm{O}$ crystals was changed by the $C_{\mathrm{Cu}}$ and $C_{\mathrm{PVA}}$ (Figure 2). The polyhedral crystals several hundred micrometers in size were formed in the lower concentration of PVA or in the absence of PVA (Figures $2 \mathrm{a}$ and $\mathrm{b}$ ). As the PVA concentration increased, the dendritic morphologies were obtained throughout the substrates (Figures 2a, c and d). The dendrites with the regularly branched angles were observed in the lower concentration region of $\mathrm{Cu}$ $\left(\mathrm{CH}_{3} \mathrm{COO}\right)_{2} \cdot \mathrm{H}_{2} \mathrm{O}$ (Figures $2 \mathrm{a}$ and $\mathrm{c}$ ), whereas the irregularly branched dendritic shapes were grown in the higher concentration region of $\mathrm{Cu}$ $\left(\mathrm{CH}_{3} \mathrm{COO}\right)_{2} \cdot \mathrm{H}_{2} \mathrm{O}$ (Figures $2 \mathrm{a}$ and $\mathrm{d}$ ). The isolated particles were only observed in the region of the lower $\mathrm{Cu}\left(\mathrm{CH}_{3} \mathrm{COO}\right)_{2} \cdot \mathrm{H}_{2} \mathrm{O}$ concentration and the higher PVA concentration (Figures $2 \mathrm{a}$ and e). The morphologies were altered from the polyhedrons to the dendritic shapes with an increase in the PVA concentration, which was consistent with our previous studies of crystal growth in polymer matrices. ${ }^{31}$ These facts suggest that the diffusion-controlled conditions were achieved on crystal growth of $\mathrm{Cu}\left(\mathrm{CH}_{3} \mathrm{COO}\right)_{2} \cdot \mathrm{H}_{2} \mathrm{O}$ in the PVA matrices.

In the present work, we focused on the $\mathrm{Cu}\left(\mathrm{CH}_{3} \mathrm{COO}\right)_{2} \cdot \mathrm{H}_{2} \mathrm{O}$ dendrites with regularly branched angles as the templates (Figure 3 ). The dendrites have branches that are $0.5-5 \mu \mathrm{m}$ in width depending on the growth conditions. The dendrite used as the template was prepared from the precursor solution containing $1.0 \mathrm{~g}$ of $\mathrm{Cu}\left(\mathrm{CH}_{3} \mathrm{COO}\right)_{2} \cdot \mathrm{H}_{2} \mathrm{O}$ and $1.0 \mathrm{~g}$ of PVA in $100 \mathrm{~g}$ of purified water (Figure 2a). The corresponding dendrite consisted of unit branches $\sim 1 \mu \mathrm{m}$ in width (Figures $3 \mathrm{a}$ and $\mathrm{b}$ ). The XRD pattern of the $\mathrm{Cu}\left(\mathrm{CH}_{3} \mathrm{COO}\right)_{2} \cdot \mathrm{H}_{2} \mathrm{O}$ dendrites shows the intensified peaks related to the (010) plane
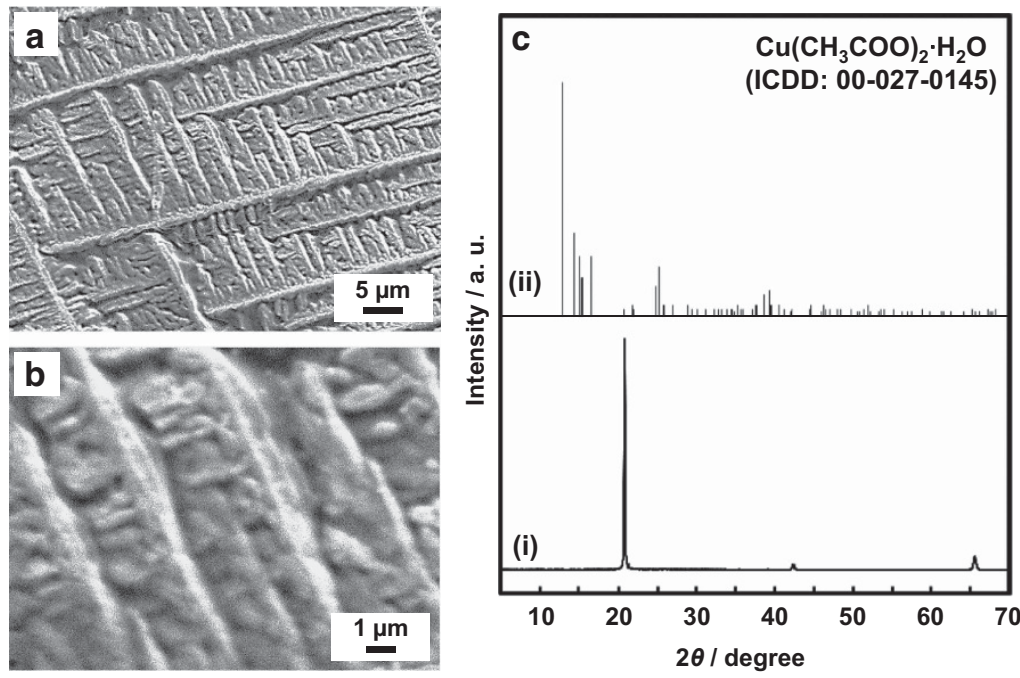

Figure 3 Scanning electron microscopy (SEM) images (a, b) and X-ray diffraction (XRD) pattern (c) of a regular dendrite wherein (i) is the resultant Cu $\left(\mathrm{CH}_{3} \mathrm{COO}\right)_{2} \cdot \mathrm{H}_{2} \mathrm{O}$ dendrite and (ii) shows the peak positions listed in the ICDD card as a template for morphogenesis formed at $C_{\mathrm{Cu}}=1.0$ and $C_{\mathrm{PVA}}=1.0$. 
a

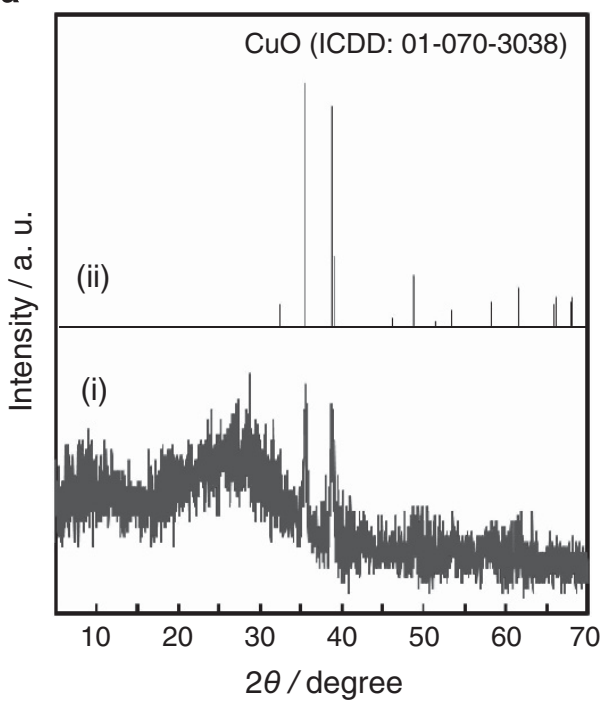

b

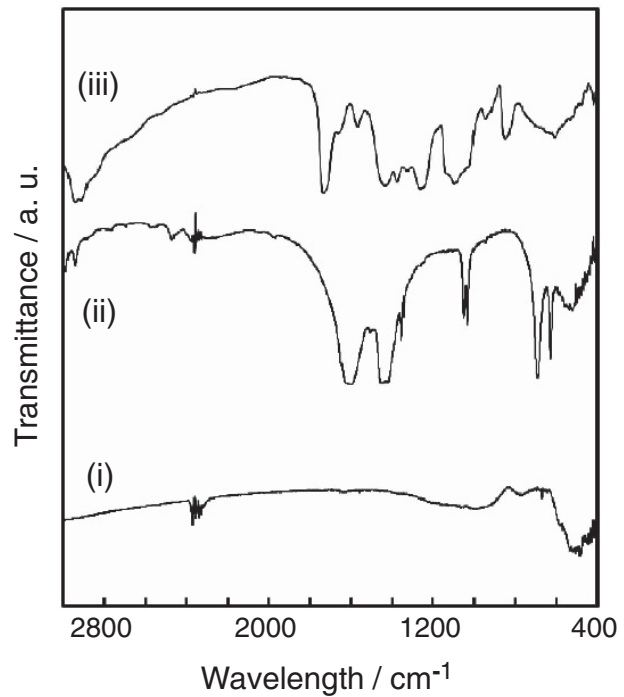

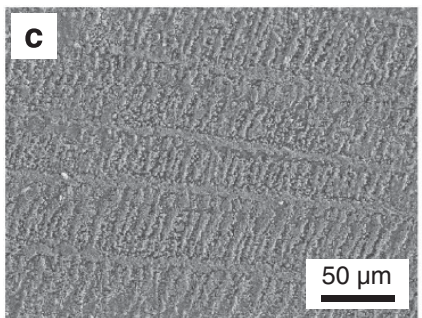
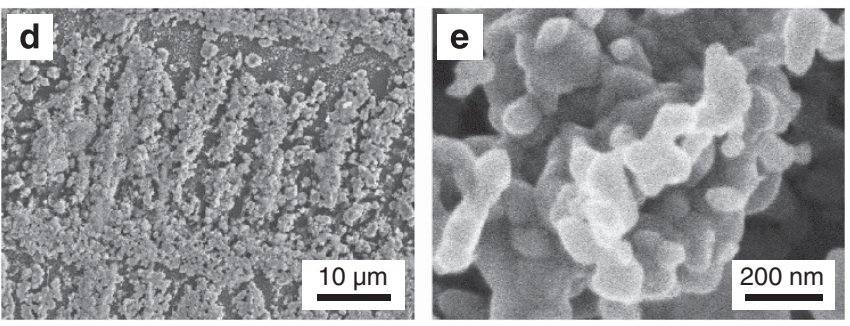

Figure 4 Dendritic morphology of CuO. (a) X-ray diffraction (XRD) patterns of the resultant CuO dendritic shape (i) and the peak positions listed in the ICDD card (ii). (b) Fourier-transform infrared absorption (FT-IR) spectra of the resultant $\mathrm{CuO}$ (i), $\mathrm{Cu}\left(\mathrm{CH}_{3} \mathrm{COO}\right)_{2} \cdot \mathrm{H}_{2} \mathrm{O}$ (ii), and commercial poly(vinyl alcohol; PVA) (iii). (c-e) Scanning electron microscopy (SEM) images of the CuO dendritic morphologies.
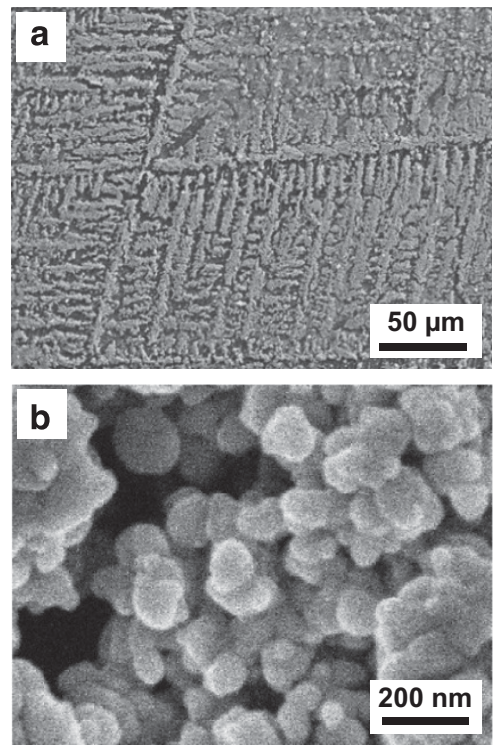

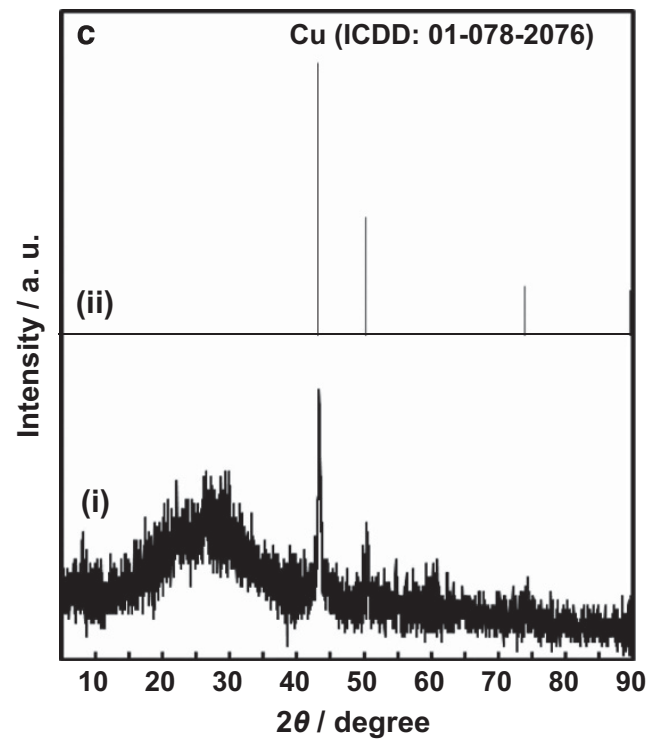

Figure 5 Dendritic morphology of $\mathrm{Cu}$. (a, b) Scanning electron microscopy (SEM) images of the resultant Cu dendritic shape. (c) X-ray diffraction (XRD) pattern of the resultant $\mathrm{Cu}$ dendritic shape (i) and the peak positions listed in the ICDD card (ii).

(Figure 3c), with three types of branched angels, namely $63^{\circ}, 61^{\circ}$ and $56^{\circ}$. On the basis of these observations, the growth directions of the branches were estimated to be (001), (100) and (101) directions of monoclinic $\mathrm{Cu}\left(\mathrm{CH}_{3} \mathrm{COO}\right)_{2} \cdot \mathrm{H}_{2} \mathrm{O}$ crystals.
Conversion from $\mathrm{Cu}\left(\mathrm{CH}_{3} \mathrm{COO}\right)_{2} \cdot \mathrm{H}_{2} \mathrm{O}$ dendrites to $\mathrm{CuO}$ dendritic shapes

The resultant $\mathrm{Cu}\left(\mathrm{CH}_{3} \mathrm{COO}\right)_{2} \cdot \mathrm{H}_{2} \mathrm{O}$ dendrites on a substrate were placed in a furnace maintained at $500^{\circ} \mathrm{C}$ for $1 \mathrm{~h}$ in an air atmosphere. 


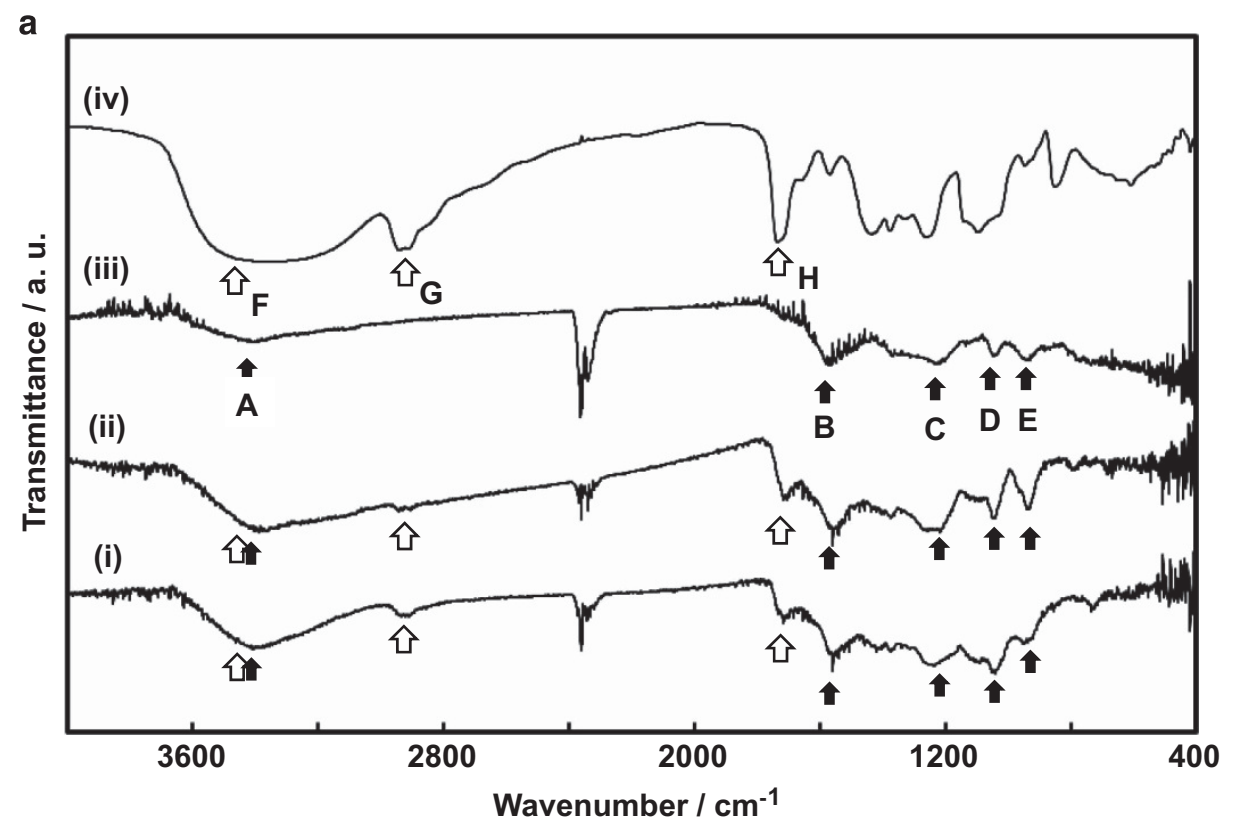

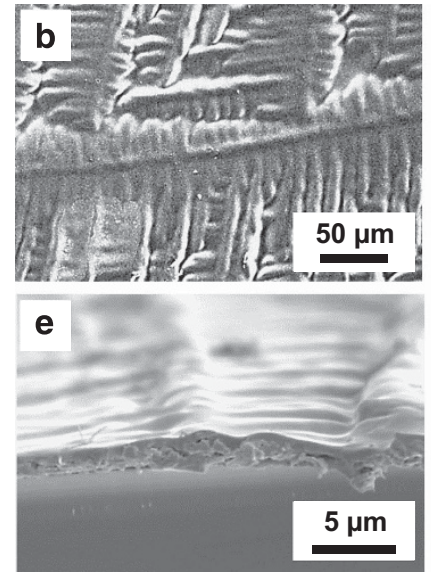

h

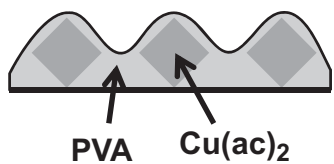

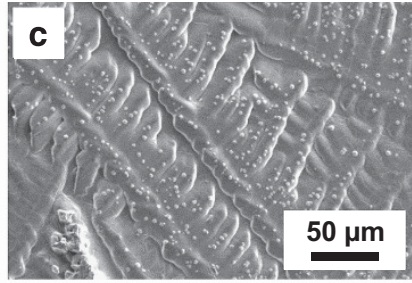
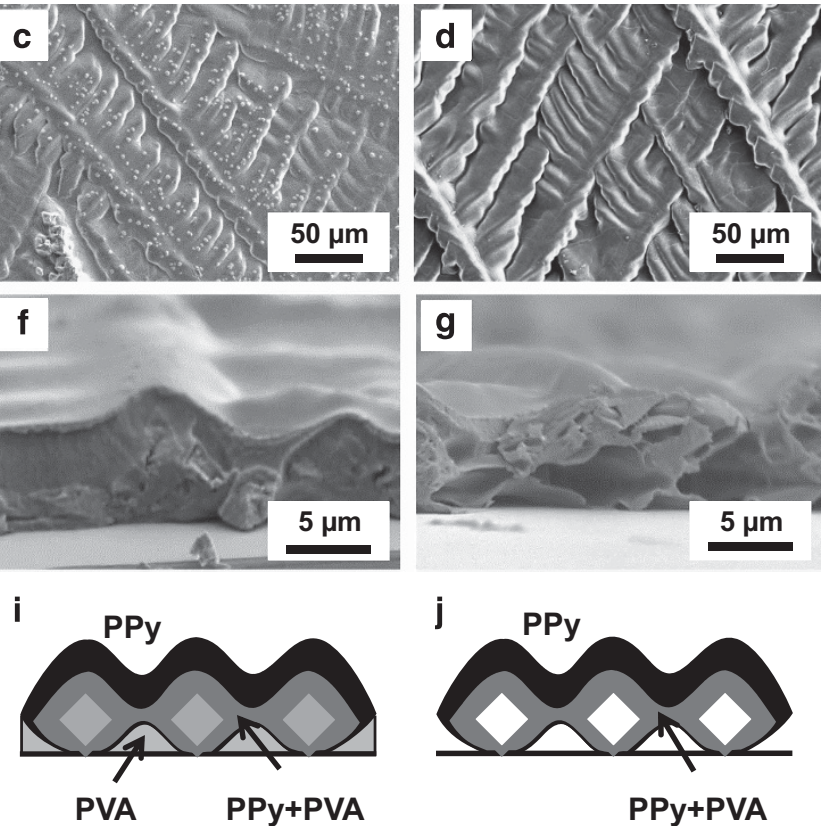
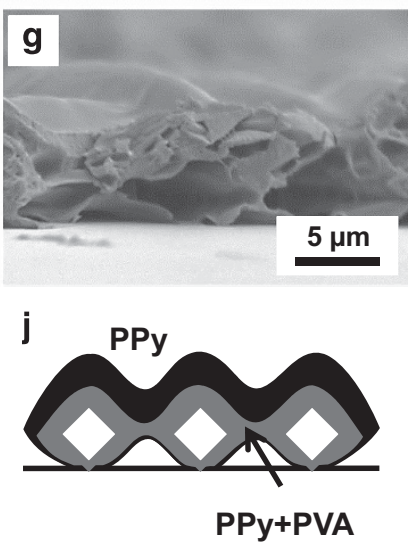

Figure 6 Morphologies of polypyrrole (PPy) dendrites synthesized from the precursor $\mathrm{Cu}\left(\mathrm{CH}_{3} \mathrm{COO}\right)_{2} \cdot \mathrm{H}_{2} \mathrm{O}$ dendrite. (a) Fourier-transform infrared absorption (FT-IR) spectra of the polymerized sample before and after the dissolution of copper-related compounds with hydrochloric acid ( $\mathrm{HCl}$, i, ii), the commercial PPy (iii) and the commercial poly(vinyl alcohol; PVA) (iv). (b-j) Scanning electron microscopy (SEM) images (b-g) and schematic illustrations ( $\mathbf{h}-\mathbf{j}$ ) of the precursor dendrite of $\mathrm{Cu}\left(\mathrm{CH}_{3} \mathrm{COO}\right)_{2} \cdot \mathrm{H}_{2} \mathrm{O}(\mathbf{b}, \mathbf{e}, \mathbf{h})$ and the polymerized sample before $(\mathbf{c}, \mathbf{f}, \mathbf{i})$ and after $(\mathbf{d}, \mathbf{g}, \mathbf{j})$ the dissolution of copper-related compounds. The absorptions in the FT-IR spectra were assigned to the following vibrations of PPy (black arrows in a-e) and PVA (white arrows in f-h): (a) N-H stretching, (b) $\mathrm{C}=\mathrm{C}$ stretching, (c) $\mathrm{C}-\mathrm{C}$ in-ring stretching, (d) $\mathrm{C}-\mathrm{H}$ ring out-of-plane bending, (e) $\mathrm{C}=\mathrm{C}$ stretching, (f) $\mathrm{O}-\mathrm{H}$ stretching vibrations in the polymeric species, (g) $\mathrm{CH}_{2}$ asymmetric stretching vibration and (h) $\mathrm{CH}_{2}$ deformation. A full color version of this figure is available at Polymer Journal online.

The color of the substrate changed from blue-green to black after the treatment (Figure $4 \mathrm{a}$ ). The peaks of the XRD pattern were assigned to those of $\mathrm{CuO}$ (Figure 4a). The FT-IR spectra showed no absorption peaks resulting from the acetate group in the precursor $\mathrm{Cu}\left(\mathrm{CH}_{3} \mathrm{COO}\right)$ ${ }_{2} \cdot \mathrm{H}_{2} \mathrm{O}$ and hydroxy group in PVA (Figure $4 \mathrm{~b}$ ), suggesting that $\mathrm{CuO}$ was obtained with the combustion of PVA and decomposition of $\mathrm{Cu}$ $\left(\mathrm{CH}_{3} \mathrm{COO}\right)_{2} \cdot \mathrm{H}_{2} \mathrm{O}$. The macroscopic dendritic morphologies were maintained on the resultant $\mathrm{CuO}$ (Figure 4c). The magnified fieldemission scanning electron microscopy images showed the branches consisting of the nanoparticles $<100 \mathrm{~nm}$ in size (Figures $4 \mathrm{~d}$ and e). The decomposition of the $\mathrm{Cu}\left(\mathrm{CH}_{3} \mathrm{COO}\right)_{2} \cdot \mathrm{H}_{2} \mathrm{O}$ crystal led to the granular $\mathrm{CuO}$ structures in the branches. When the precursor dendrite of $\mathrm{Cu}\left(\mathrm{CH}_{3} \mathrm{COO}\right)_{2} \cdot \mathrm{H}_{2} \mathrm{O}$ was heated from room temperature to $500^{\circ} \mathrm{C}$ by a slower heating rate of $1^{\circ} \mathrm{C} \mathrm{min}-1$, the macroscopic dendritic shape collapsed with the combustion of PVA. Therefore, the rapid heating operation without the temperature rising step is required for the simultaneous removal of the acetate groups and PVA to keep the dendritic morphology. In the slower heating process, the prior 

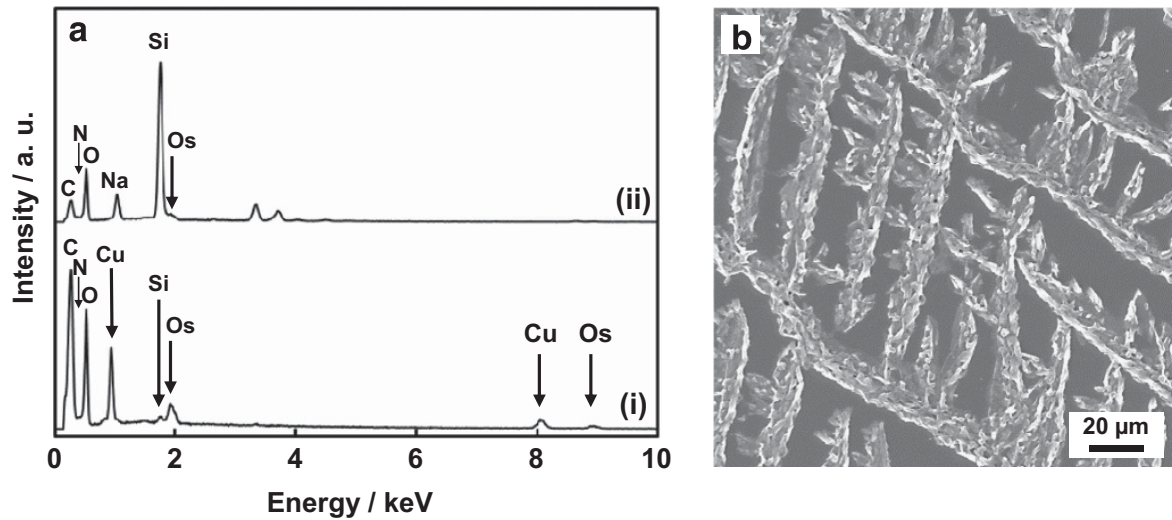

Figure 7 Energy dispersive X-ray (EDX) spectra (a) and field-emission scanning electron microscopy (FESEM) image (b) of the polymerized samples before (i) and after (ii) dissolution of the copper-related compounds with hydrochloric acid $(\mathrm{HCl})$. The $\mathrm{Si}$ and Na peaks were caused by glass substrates. The Os peak is ascribed to the conductive coating of amorphous osmium. The $\mathrm{Cu}$ peak was not detected after $\mathrm{HCl}$ treatment. The FESEM image in panel $\mathbf{b}$ corresponds to the area for the collection of the EDX spectrum in panel a.

combustion of PVA led to the collapse of the $\mathrm{Cu}\left(\mathrm{CH}_{3} \mathrm{COO}\right)_{2} \cdot \mathrm{H}_{2} \mathrm{O}$ dendritic morphology. The rapid heating process facilitated the decomposition of $\mathrm{Cu}\left(\mathrm{CH}_{3} \mathrm{COO}\right)_{2} \cdot \mathrm{H}_{2} \mathrm{O}$ to $\mathrm{CuO}$ prior to the combustion of PVA.

\section{Conversion from $\mathrm{CuO}$ dendritic shapes to metallic $\mathrm{Cu}$ ones}

The resultant $\mathrm{CuO}$ dendritic morphologies on a substrate were immersed in an aqueous solution containing $10 \mathrm{mmol} \mathrm{dm}^{-3}$ of $\mathrm{DMAB}$ for $3 \mathrm{~h}$ at room temperature. After the reaction, the color of the substrate changed from black to brown (the inset of Figure 5a). The macroscopic dendritic morphologies consisting of the nanocrystals $<100 \mathrm{~nm}$ in size were maintained after the immersion in DMAB aqueous solution (Figures $5 \mathrm{a}$ and $\mathrm{b}$ ). The $\mathrm{Cu}$ peaks were observed on the XRD pattern (Figure $5 \mathrm{c}$ ), the reduction from $\mathrm{CuO}$ to $\mathrm{Cu}$ proceeded without the collapse of the dendritic morphologies. When hydrazine $\left(\mathrm{N}_{2} \mathrm{H}_{4}\right)$ was used as a reducing agent, the morphologies were not maintained after the immersion in the solution. The morphology is not maintained in the aqueous solution of $\mathrm{N}_{2} \mathrm{H}_{4}$ as ammonia that is generated in the reduction processes promotes the dissolution of $\mathrm{CuO}$, the low solubility of $\mathrm{CuO}$ in an aqueous solution of DMAB facilitates the gradual reduction to $\mathrm{Cu}$ without morphology alteration.

Formation of PPy on the surface of $\mathrm{Cu}\left(\mathrm{CH}_{3} \mathrm{COO}\right)_{2} \cdot \mathrm{H}_{2} \mathrm{O}$ dendrites The resultant $\mathrm{Cu}\left(\mathrm{CH}_{3} \mathrm{COO}\right)_{2} \cdot \mathrm{H}_{2} \mathrm{O}$ dendrites on the substrate were put in a glass bottle containing a neat liquid of pyrrole (Py) at $60^{\circ} \mathrm{C}$ for $24 \mathrm{~h}$ (Figures 1a and $\mathrm{d}$ ). The vapor of Py monomer was supplied to the surface of $\mathrm{Cu}\left(\mathrm{CH}_{3} \mathrm{COO}\right)_{2} \cdot \mathrm{H}_{2} \mathrm{O}$ dendrites. The color of the substrate changed from blue-green to black. The FT-IR spectra showed the formation of PPy after the reaction (Figure 6a). The characteristic absorptions of PPy were observed on the resultant PPy ${ }^{61,62}$ After the dissolution of the copper-related compounds by $\mathrm{HCl}$, the absorptions assigned to PPy and PVA were observed on the FT-IR spectra (the spectra (i) and (iii) in Figure 6a). ${ }^{63-65}$ The absorptions of PVA in the FT-IR spectra indicate the presence of the remaining PVA (the spectra (i) and (iv) in Figure 6a). In addition, the energy dispersive $\mathrm{X}$-ray spectra show that the copper-related compounds were dissolved after the $\mathrm{HCl}$ treatment (Figure 7). The dendritic morphologies of $\mathrm{Cu}\left(\mathrm{CH}_{3} \mathrm{COO}\right)_{2} \cdot \mathrm{H}_{2} \mathrm{O}$ were maintained after the polymerization and subsequent dissolution of the original dendrite (Figures $6 \mathrm{~b}-\mathrm{g}$ ), and the cross-sectional images suggest polymerization behavior (Figures 6h-j). The original $\mathrm{Cu}\left(\mathrm{CH}_{3} \mathrm{COO}\right)_{2} \cdot \mathrm{H}_{2} \mathrm{O}$ dendrites were formed in the PVA matrix film $\sim 1 \mu \mathrm{m}$ in thickness on the substrate (Figures $6 \mathrm{e}$ and $\mathrm{h}$ ). After the polymerization, the thickness was increased to $\sim 5 \mu \mathrm{m}$ with the formation and incorporation of PPy in the PVA matrix film (Figures $6 \mathrm{f}$ and $\mathrm{i}$ ). The oxidative polymerization of Py proceeds around the $\mathrm{Cu}\left(\mathrm{CH}_{3} \mathrm{COO}\right)_{2} \cdot \mathrm{H}_{2} \mathrm{O}$ dendrite including the PVA matrices through the diffusion of $\mathrm{Py}$ and the reduction of $\mathrm{Cu}\left(\mathrm{CH}_{3} \mathrm{COO}\right)_{2} \cdot \mathrm{H}_{2} \mathrm{O}$ (Figure 6i). The remaining unreacted $\mathrm{Cu}$ $\left(\mathrm{CH}_{3} \mathrm{COO}\right)_{2} \cdot \mathrm{H}_{2} \mathrm{O}$ crystals and PVA matrices near the substrate are dissolved by the $\mathrm{HCl}$ treatment (Figures $6 \mathrm{i}$ and $\mathrm{j}$ ). In contrast, the composite film of PPy and PVA remains after dissolution by $\mathrm{HCl}$. The composite films of PPy and PVA with the hollow interior are obtained (Figures 6f, g, i and j). The formation of the composite with PVA involves the preservation of the PPy dendritic shape. In this way, the dendritic morphologies of the original $\mathrm{Cu}\left(\mathrm{CH}_{3} \mathrm{COO}\right)_{2} \cdot \mathrm{H}_{2} \mathrm{O}$ were replicated to $\mathrm{PPy}$.

\section{CONCLUSION}

The dendrites of $\mathrm{Cu}\left(\mathrm{CH}_{3} \mathrm{COO}\right)_{2} \cdot \mathrm{H}_{2} \mathrm{O}$, a transition metal salt, were grown in a PVA matrix, which was facilitated by the diffusioncontrolled condition within a polymer matrix. The dendritic morphologies of $\mathrm{CuO}$ with the porous structures were obtained by the thermal treatment of the original $\mathrm{Cu}\left(\mathrm{CH}_{3} \mathrm{COO}\right)_{2} \cdot \mathrm{H}_{2} \mathrm{O}$ dendrite. The subsequent reduction of the resultant $\mathrm{CuO}$ by using $\mathrm{DMAB}$ provided the metallic $\mathrm{Cu}$ with the dendritic shapes. The oxidative polymerization of Py was achieved on the $\mathrm{Cu}\left(\mathrm{CH}_{3} \mathrm{COO}\right)_{2} \cdot \mathrm{H}_{2} \mathrm{O}$ dendrites through the reduction of copper ions in the PVA matrix film. The dendritic morphology of PPy was obtained with the PVA matrix film after the dissolution of the copper-related compounds. In this way, the dendritic morphologies of $\mathrm{CuO}, \mathrm{Cu}$ and $\mathrm{PPy}$ were obtained from the dendrites of $\mathrm{Cu}\left(\mathrm{CH}_{3} \mathrm{COO}\right)_{2} \cdot \mathrm{H}_{2} \mathrm{O}$ as the template. The present study shows that the approach can be applied to morphogenesis of a variety of metal oxides, metal and conductive polymers by using the morphology-controlled crystals of transition metal salts.

\section{ACKNOWLEDGEMENTS}

This work was partially supported by a Grant-in-Aid for Scientific Research (no. 22107010) on the Innovative Areas: 'Fusion Materials' (area no. 2206) from the Ministry of Education, Culture, Sports, Science and Technology (MEXT). 
1 Mann, S. Molecular recognition in biomineralization. Nature 332, 119-124 (1988).

2 Addadi, L. \& Weiner, S. Control and design principles in biological mineralization. Angew. Chem. Int. Ed. Engl. 31, 153-169 (1992).

3 Bäuerlein, E., Behrens, P. \& Epple, M. Handbook of Biomineralization (Wiley-VCH: Weinheim, 2007).

4 Mann, S. Molecular tectonics in biomineralization and biomimetic materials chemistry. Nature 365, 499-505 (1993).

5 Kato, T. Polymer/calcium carbonate layered thin-film composites. Adv. Mater. 12 1543-1546 (2000).

6 Naka, K. \& Chujo, Y. Control of crystal nucleation and growth of calcium carbonate by synthetic substrates. Chem. Mater. 13, 3245-3259 (2001).

7 Kato, T., Sugawara, A. \& Hosoda, N. Calcium carbonate-organic hybrid materials. Adv. Mater. 14, 869-877 (2002).

8 Yu, S.-H. \& Cölfen, H. Bio-inspired crystal morphogenesis by hydrophilic polymers. J. Mater. Chem. 14, 2124-2147 (2004).

9 Imai, H., Oaki, Y. \& Kotachi, A. A biomimetic approach for hierarchically structured inorganic crystals through self-organization with polymeric molecules. Bull. Chem. Soc Jpn. 79, 1834-1851 (2006).

10 Xu, A. W., Ma, Y. \& Cölfen, H. Biomimetic mineralization. J. Mater. Chem. 17, 415-449 (2007).

11 Meldrum, F. C. \& Cölfen, H. Controlling mineral morphologies and structures in biological and synthetic systems. Chem. Rev. 108, 4332-4432 (2008).

12 Sommerdijk, N. A. \& de With, G. Biomimetic $\mathrm{CaCO}_{3}$ mineralization using designer molecules and interfaces. Chem. Rev. 108, 4499-4550 (2008).

13 Kato, T., Sakamoto, T. \& Nishimura, T. Macromolecular templating for the formation of inorganic-organic hybrid structures. MRS Bull. 35, 127-132 (2010).

14 Imai, H. \& Oaki, Y. Bioinspired hierarchical crystals. MRS Bull. 35, 138-144 (2010).

15 Tanaka, Y. \& Naka, K. Synthesis of calcium carbonate particles with carboxylicterminated hyperbranched poly(amidoamine) and their surface modification. Polym. J. 44, 586-593 (2013)

16 Takaguchi Y., Yanagimoto Y., Tajima T., Ohta K., Motoyoshiya J. \& Aoyama H. Photodimerization of anthracene having dendritic substituent within the vaterite crystals of $\mathrm{CaCO}_{3}$. Chem. Lett. 31, 1102-1103 (2002)

17 Qi L., Cölfen H., Antonietti M., Li M., Hopwood J. D., Ashley A. J. \& Mann S. Formation of $\mathrm{BaSO}_{4}$ fibres with morphological complexity in aqueous polymer solutions. Chem. Eur. J. 7, 3526-3532 (2001)

$18 \mathrm{Yu}, \mathrm{S}$. H., Antonietti, M., Cölfen, H. \& Hartmann, J. Growth and self-assembly of $\mathrm{BaCrO}_{4}$ and $\mathrm{BaSO}_{4}$ nanofibers toward hierarchical and repetitive superstructures by polymer-controlled mineralization reactions. Nano Lett. 3, 379-382 (2003).

19 Oaki, Y. \& Imai, H. Hierarchically organized superstructure emerging from exquisite association of inorganic crystals, organic polymers, and dyes: a model approach toward suprabiomineral material. Adv. Funct. Mater. 15, 1407-1414 (2005).

20 Oaki, Y., Hayashi, S. \& Imai, H. A hierarchical self-similar structure of oriented calcite with association of an agar gel matrix: inheritance of crystal habit from nanoscale. Chem. Commun 27, 2841-2843 (2007).

21 Cölfen, H. \& Antonietti, M. Mesocrystals: Inorganic superstructures made by highly parallel crystallization and controlled alignment. Angew. Chem. Int. Ed. 44, 5576-5591 (2005)

22 Niederberger, M. \& Cölfen, H. Oriented attachment and mesocrystals: Non-classical crystallization mechanisms based on nanoparticle assembly. Phys. Chem. Phys. Chem. 8, 3271-3287 (2006).

23 Zhou, L. \& O'Brien, P. Mesocrystals: a new class of solid materials. Small 4 1566-1574 (2008).

24 Oaki, Y. \& Imai, H. The hierarchical architecture of nacre and its mimetic material. Angew. Chem. Int. Ed. 44, 6571-6575 (2005).

25 Oaki, Y. \& Imai, H. Nanoengineering in echinoderms: emergence of morphology from nanobricks. Small 2, 66-71 (2006).

26 Oaki, Y., Kotachi, A., Miura, T. \& Imai, H. Bridged nanocrystals in biominerals and their biomimetics: classical yet modern crystal growth on the nanoscale. Adv. Funct. Mater. 16, 1633-1639 (2006).

27 Sugawara, A., Ishii, T. \& Kato, T. Self-organized calcium carbonate with regular surface relief structures. Angew. Chem. Int. Ed. 42, 5299-5303 (2003).

28 Sakamoto, T., Oichi, A., Sugawara, A. \& Kato, T. Self-organization of patterned $\mathrm{CaCO}_{3} /$ polymer composite films: tuning of their morphologies by the change of molecular weights of acidic polymers. Chem. Lett. 35, 310 (2006).

29 Sakamoto, T. Oichi, A. Nishimura, T. Sugawara, A \& Kato, T. Calcium carbonate/polymer thin-film hybrids: induction of the formation of patterned aragonite crystals by thermal treatment of a polymer matrix. Polym. J. 41, 522-523 (2009).

30 Sakamoto T., Oichi A., Oaki Y., Nishimura T., Sugawara A. \& Kato T. Three-dimensional relief structures of $\mathrm{CaCO}_{3}$ crystal assemblies formed by spontaneous two-step crystal growth on a polymer thin film. Cryst. Growth Des. 9, 622-625 (2009)

31 Oaki, Y. \& Imai, H. Experimental demonstration for the morphological evolution of crystals grown in gel media. Cryst. Growth Des. 3, 711-716 (2003).

32 Oaki, Y., Adachi, R. \& Imai, H. Self-organization of hollow-cone carbonate crystals through molecular control with an acid organic polymer. Polym. J. 44, 612-619 (2012)

33 Henisch, H. K. In Crystals in Gels and Liesegang Rings (Cambridge University Press: Cambridge, 1988)
34 Liu, X. Y. \& Swant, P. D. Micro/nanoengineering of self-organized three-dimensional fibrous structure of functional materials. Angew. Chem. Int. Ed. 41, 3641-3645 (2002).

35 Petrova, P. I. \& Swift, J. A. Habit changes of sodium bromate crystals grown from gel media. Cryst. Growth Des. 2, 573-578 (2002)

36 Imai, H. \& Oaki, Y. Emergence of morphological chirality with twinned crystals. Angew. Chem. Int. Ed. 43, 1363-1368 (2004).

37 Oaki, Y. \& Imai, H. Amplification of chirality from molecules into morphology of crystals through molecular recognition. J. Am. Chem. Soc. 126, 9271-9275 (2004).

38 Oaki, Y. \& Imai, H. Stereospecific morphogenesis of aspartic acid helical crystals through molecular recognition. Langmuir 23, 5466-5470 (2007).

39 Imai, H. \& Oaki, Y. Emergence of helical morphologies with crystals: twisted growth under diffusion-limited conditions and chirality control with molecular recognition. Cryst. Eng. Comm. 12, 1679-1687 (2010).

40 Tokutomi, D., Ise, R., Oaki, Y. \& Imai, H. Spontaneous formation of 2D micropatterns with straight and/or curving dendrites through crystal growth of $\mathrm{Ba}\left(\mathrm{NO}_{3}\right)_{2}$ in polymer matrix. Cryst. Growth Des. 13, 3011-3017 (2013).

41 Ise, R., Oaki, Y. \& Imai, H. Formation of trigonal microarrays with cubic $\mathrm{Ba}\left(\mathrm{NO}_{3}\right)_{2}$ in a polymer matrix. J. Cer. Soc. Jpn 121, 555-558 (2013).

42 Saito, Y. \& Ueta, T. Monte Carlo studies of equilibrium and growth shapes of a crystal. Phys. Rev. A 40, 3408-3419 (1989).

43 Kato, T., Suzuki, T., Amamiya, T., Irie, T. \& Komiyama, M. Effects of macromolecules on the crystallization of $\mathrm{CaCO}_{3}$ : The formation of organic/inorganic composites. Supramol. Sci. 5, 411-415 (1998).

44 Kato, T. \& Amamiya, T. A new approach to organic/inorganic composites. Thin film coating of $\mathrm{CaCO}_{3}$ on a chitin fiber in the presence of acid-rich macromolecules. Chem. Lett. 199 (1999)

45 Kato, T., Suzuki, T. \& Irie, T. Layered thin-film composite consisting of polymers and calcium carbonate: a novel organic/inorganic material with an organized structure. Chem. Lett. 29, 186-187 (2000).

46 Hosoda, N. \& Kato, T. Thin-film formation of calcium carbonate crystals: effects of functional groups of matrix polymers. Chem. Mater. 13, 688 (2001).

47 Hosoda, N., Sugawara, A. \& Kato, T. Template effect of crystalline poly(vinyl alcohol) for selective formation of aragonite and vaterite $\mathrm{CaCO}_{3}$ thin films. Macromolecules 36, 6449-6452 (2003).

48 Sugawara, A., Nishimura, T., Yamamoto, Y., Inoue, H., Nagasawa, H. \& Kato, T. et al. Self-organization of oriented calcium carbonate/polymer composites: Effects of a matrix peptide isolated from the exoskeleton of a crayfish. Angew. Chem. Int. Ed. 45, $2876-2879$ (2006).

49 Nishimura, T., Ito, T., Yamamoto, Y., Yoshio, M. \& Kato, T. Macroscopically ordered polymer $/ \mathrm{CaCO}_{3}$ hybrids prepared by using a liquid-crystalline template. Angew. Chem. Int. Ed. 47, 2800-2803 (2008).

50 Yamamoto, Y., Nishimura, T., Saito, T. \& Kato, T. $\mathrm{CaCO}_{3} /$ chitin-whisker hybrids: formation of $\mathrm{CaCO}_{3}$ crystals in chitin-based liquid-crystalline suspension. Polym. J. 42, 583-586 (2010).

51 Sakamoto, T., Nishimura, Y. Nishimura, T \& Kato, T. Photoimaging of self-organized $\mathrm{CaCO}_{3} /$ polymer hybrid films by formation of regular relief and flat surface morphologies. Angew. Chem. Int. Ed. 50, 5856 (2011).

52 Han, Y., Nishimura, T. \& Kato, T. Morphology tuning in the formation of vaterite crystal thin films with thermoresponsive poly(n-isopropylacrylamide) brush matrices. Cryst. Eng. Comm. 16, 3540-3547 (2014)

53 Zhu, F., Nishimura, T., Eimura, H. \& Kato, T. Supramolecular effects on formation of $\mathrm{CaCO}_{3}$ thin films on a polymer matrix. Cryst. Eng. Comm. 16, 1496-1501 (2014).

54 van Bommel, K. J. C., Friggeri, A. \& Shinkai, S. Organic templates for the generation of inorganic materials. Angew. Chem. Int. Ed. 42, 980-999 (2003).

55 Ruiz-Hitzky, E. Conducting polymers intercalated in layered solids. Adv. Mater. 5 , 334-340 (1993)

56 Horike, S., Shimomura, S. \& Kitagawa, S. Soft porous crystals. Nat. Chem. 1, 695-704 (2009)

57 Uemura, T., Yanai, N. \& Kitagawa, S. Polymerization reactions in porous coordination polymers. Chem. Soc. Rev. 38, 1228-1236 (2009).

58 Bhattacharyya, D., Howden, R. M., Borrelli, D. C. \& Gleason, K. K. Vapor phase oxidative synthesis of conjugated polymers and applications. J. Polym. Sci. B Polym. Phys. 50, 1329-1351 (2012).

$59 \mathrm{Im}$, S. G., Yoo, P. J., Hammond, P. T. \& Gleason, K. K. Grafted conducting polymer films for nano-patterning onto various organic and inorganic substrates by oxidative chemical vapor deposition. Adv. Mater. 19, 2863-2867 (2007).

60 Xu Y., Wang H., Zhu R., Liu C., Wu X. \& Zhang B. Conversion of CuO nanoplates into porous hybrid $\mathrm{Cu}_{2} \mathrm{O}$ /polypyrrole nnoflakes through a pyrrole-induced reductive transformation reaction. Chem. Asian. J. 8, 1120-1127 (2013)

61 Kostić, R., Raković, D., Stepanyan, S. A., Davidova, I. E. \& Gribov, L. A. Vibrational spectroscopy of polypyrrole, theoretical study. J. Chem. Phys. 102, 3104-3109 (1995).

62 Tian, B. \& Zerbi, G. Lattice dynamics and vibrational spectra of polypyrrole. J. Chem. Phys. 92, 3886-3891 (1990).

63 Tajima, T., Tsutsui, A., Fujii, T., Takada, J. \& Takaguchi, Y. Fabrication of novel coreshell microspheres consisting of single-walled carbon nanotubes and $\mathrm{CaCO}_{3}$ through biomimetic mineralization. Polym. J. 44, 620-624 (2013).

64 Kotachi, A. \& Imai, H. Polymorph control of calcium carbonate films in a poly(acrylic acid)-chitosan system. Cryst. Growth Des. 6, 1636-1641 (2006).

65 Kotachi, A. \& Imai, H. Development of ordered calcium carbonate microarrays from polymorph specific planar films. Chem. Lett. 35, 204-205 (2006). 